\title{
Direct catalytic arylation of heteroarenes with meso-bromophenyl-substituted porphyrins
}

\author{
Alexei N. Kiselev ${ }^{1}$, Olga K. Grigorova ${ }^{2}$, Alexei D. Averin ${ }^{2}$, Sergei A. Syrbu ${ }^{1}$, \\ Oskar I. Koifman ${ }^{3}$ and Irina P. Beletskaya*2
}

\section{Full Research Paper}

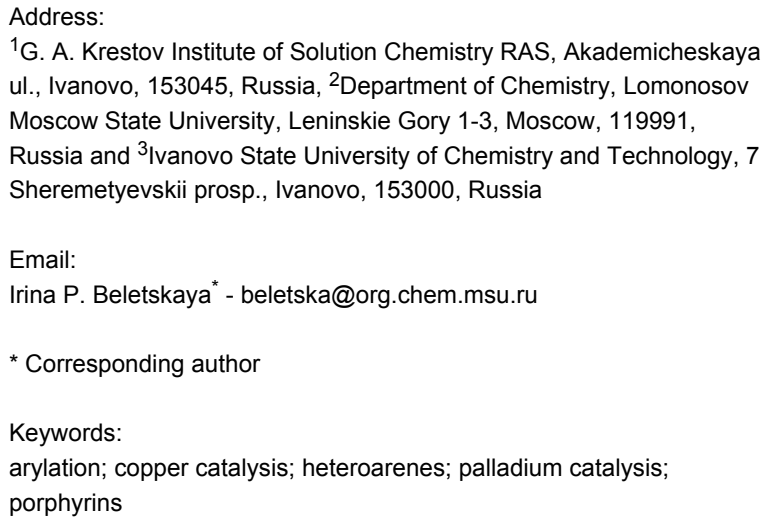

${ }^{1} \mathrm{G}$. A. Krestov Institute of Solution Chemistry RAS, Akademicheskaya ul., Ivanovo, 153045, Russia, ${ }^{2}$ Department of Chemistry, Lomonosov Moscow State University, Leninskie Gory 1-3, Moscow, 119991, Russia and ${ }^{3}$ Ivanovo State University of Chemistry and Technology, 7 Sheremetyevskii prosp., Ivanovo, 153000, Russia

Email:

Irina P. Beletskaya* - beletska@org.chem.msu.ru

${ }^{*}$ Corresponding author

Keywords:

arylation; copper catalysis; heteroarenes; palladium catalysis; porphyrins

Beilstein J. Org. Chem. 2017, 13, 1524-1532.

doi:10.3762/bjoc. 13.152

Received: 09 March 2017

Accepted: 22 June 2017

Published: 03 August 2017

Associate Editor: I. Marek

(c) 2017 Kiselev et al.; licensee Beilstein-Institut. License and terms: see end of document.

\begin{abstract}
The arylation of mono-, di- and tetra-meso-bromophenyl-substituted porphyrins with the heteroarenes containing "acidic" $\mathrm{C}-\mathrm{H}$ bonds, such as benzoxazole, benzothiazole and $\mathrm{N}$-methylimidazole was studied in the presence of three alternative catalytic systems: $\mathrm{Pd}(\mathrm{dba})_{2} / \mathrm{DavePhos} / \mathrm{Cs}_{2} \mathrm{CO}_{3}, \mathrm{Pd}\left(\mathrm{PPh}_{3}\right)_{4} / \mathrm{PivOH} / \mathrm{K}_{2} \mathrm{CO}_{3}$ and $\mathrm{Pd}(\mathrm{OAc})_{2} / \mathrm{Cu}(\mathrm{OAc})_{2} / \mathrm{PPh}_{3} / \mathrm{K}_{2} \mathrm{CO}_{3}$. The first catalytic system was found to be successful in the reaction with benzoxazole, the second one was less efficient for our purpose, while the third system proved to be most versatile and afforded corresponding mono-, di-, tri- and even tetraarylated derivatives of porphyrins.
\end{abstract}

\section{Introduction}

Porphyrins play an outstanding role in many fields of modern organic chemistry due to their unique structure and electronic properties. These molecules have already proved to be powerful tools in phototherapy, radioimmunotherapy and imaging [1], for cancer treatment [2], and actually sophisticated theranostic porphyrin-based nanodevices have been developed for guided photodynamic therapy [3]. On the other hand, various heterocycles also find multiple medical applications: bis(benzimidazoles), bis(benzoxazoles) and benzothiazoles display anticancer activities [4], 2-arylbenzothiazole is a privileged scaffold in drug discovey, and the main areas of application of such medicaments are antitumor remedies and non-invasive diagnostic imaging agents for PET, SPECT and MRI methods [5].

The combination of porphyrin and heterocyclic moieties in one molecule is perspective for the design of new compounds with potential powerful pharmaceutical properties. Up to date certain tetrapyrrole derivatives of such type were described in the literature, for example, porphyrins with imidazole and benzimidazole substitutents at meso-positions [6,7], meso-pyridinyl 
and meso-quinolinyl-substituted porphyrins [8], an imidazolyl group was attached to the meso-position also via acetylene bridge [9]. All these compounds were synthesized from the corresponding aldehydes already possessing an heteroaromatic moiety.

The development of the catalytic approaches opened an easy access to 2-aryl-substituted benzothiazoles, benzoxazoles and benzimidazoles. Kumada-Tamao-Corriu [10,11], Suzuki-Miyaura [12-15] and Stille couplings [16-22] were successfully applied for this purpose. Direct arylation and alkenylation are modern approaches for the formation of $\mathrm{C}-\mathrm{C}$ bonds, and the application of these methodologies to porphyrins was widely studied by Osuka and co-workers. Their research was targeted at the Ir-catalyzed $\beta$-borylation of porphyrins and zinc porphyrinates with the purpose of the consequent synthesis of di- and polyporphyrin structures [23-25], further direct $\beta$-arylation of tetrapyrrolic systems with aryl bromides was developed using the $\mathrm{Pd}(\mathrm{OAc})_{2} / \mathrm{DavePhos} / \mathrm{PivOH}$ catalytic system (DavePhos = 2-dicyclohexylphosphine-2'-dimethylaminobiphenyl, $\mathrm{PivOH}=t$-BuCOOH) [26,27], and also bromo derivatives of condensed aromatic compounds were employed in this process [28]. The results of the Osuka group and other researchers in this field were overviewed in a short review [29]. The main features of these reactions are exclusive arylation in $\beta$-position of porphyrins and necessity to use great excesses (10-20 equiv) of aryl bromides as well as large catalyst loadings (20-30 mol \% Pd(0), 40-50 mol \% DavePhos). Only Ni porphyrinates were described in the arylation reactions.

In this connection we considered it important to develop an alternative approach to heteroaryl-substituted porphyrins using catalytic arylation of easily accessible meso-(bromophenyl)porphyrins with heterocycles possessing "acidic" $\mathrm{C}-\mathrm{H}$ bonds, such as benzoxazole ( $\left.\mathrm{p} K_{\mathrm{a}} 24.4\right)$, benzothiazole $\left(\mathrm{p} K_{\mathrm{a}} 27.3\right)$, and $N$-methylbenzimidazole ( $K_{\mathrm{a}} 32.5$ ) [30]. Starting mono- and di( $p$-bromophenyl)-substituted porphyrins $\mathbf{1}$ and $\mathbf{1 1}$ were synthesized according to a described procedure [31], their ana- logues 2, 10, 12 were obtained using essentially the same approach.

\section{Results and Discussion}

Zinc meso-(4-bromophenyl)porphyrinate (1) was chosen as a model substrate for the investigation of the conditions of the catalytic arylation. The reaction with benzothiazole was first catalyzed with $\mathrm{Pd}(\mathrm{OAc})_{2} /$ DavePhos (2-dicyclohexylphosphino2'-dimethylaminobiphenyl) (20:20 mol \%) and carried out in $\mathrm{DMF}$ at $150{ }^{\circ} \mathrm{C}$ in the presence of $\mathrm{Cs}_{2} \mathrm{CO}_{3}$ as a base for $24 \mathrm{~h}$, however, these conditions were unfavorable and provided only $8 \%$ yield of the target coupling product 3 (Scheme 1, Table 1, entry 1).

The reaction obviously needs zerovalent palladium for the catalytic cycle and we suppose that Pd(II) was partially reduced by the phosphine ligand. The application of another catalytic system with $\operatorname{Pd}(0), \operatorname{Pd}(\mathrm{dba})_{2} /$ DavePhos $(20: 22 \mathrm{~mol} \%$, dba $=$ dibenzylideneacetone) together with a $100 \%$ excess of benzothiazole was more successful as it afforded $32 \%$ yield of compound 3 (Table 1, entry 2); it is interesting that the use of dioxane instead of DMF and the decrease in the reaction temperature down to $100{ }^{\circ} \mathrm{C}$, did not notably change the yield of $\mathbf{3}$ (34\%, Table 1, entry 3$)$. The use of porphyrin in excess diminished the yield (Table 1, entry 4). The reaction of benzoxazole with a more acidic $\mathrm{C}-\mathrm{H}$ bond resulted in a high yield of the coupling product $4(83 \%$, Table 1 , entry 5$)$, though equimolar amounts of starting compounds were used. It means that the nature of the $\mathrm{C}-\mathrm{H}$ bond is crucial for the result of the coupling and the nature of the catalytic system including the solvent should be adjusted to the certain pair of the reagents. Moreover, the changes in the reaction conditions may lead to the change of the mechanism of the arylation process. For example, the arylation of benzoxazole mediated by $\mathrm{Pd}(\mathrm{OAc})_{2} / \mathrm{PPh}_{3}$ presumably includes the cleavage of the 5-membered heterocycle with the formation of the transient isocyanide Pd complex followed by the ring closure [32]; on the other hand, the arylation of benzothiophene in the presence of $\mathrm{Pd}(\mathrm{OAc})_{2} / \mathrm{PCy}_{3} * \mathrm{HBF}_{4} / \mathrm{PivOH}$

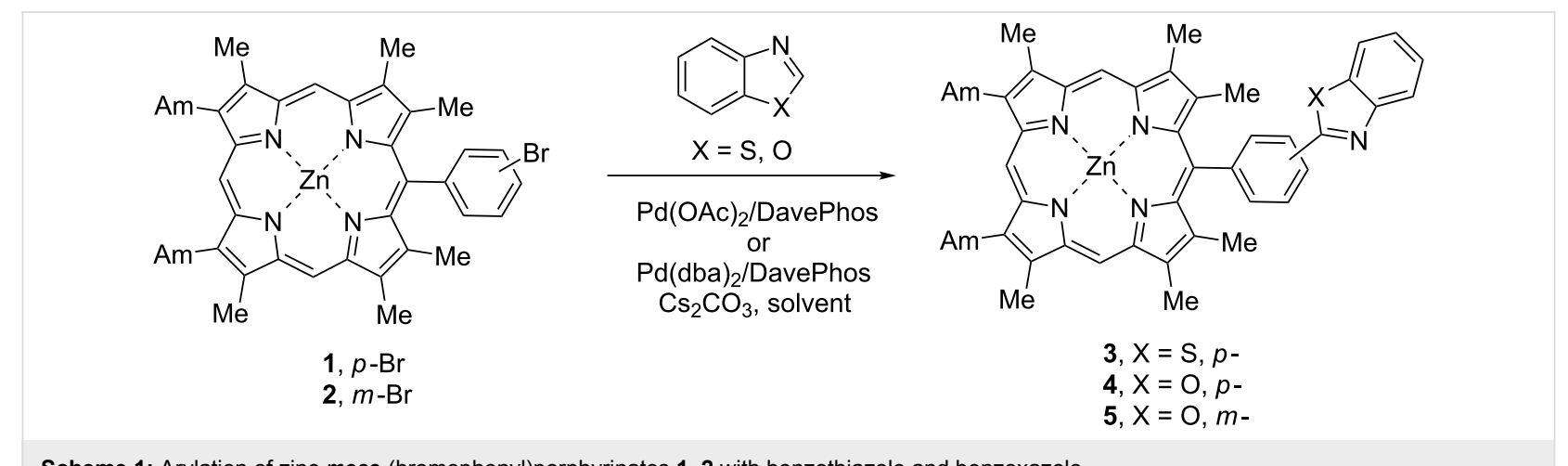

Scheme 1: Arylation of zinc meso-(bromophenyl)porphyrinates 1, 2 with benzothiazole and benzoxazole 


\begin{tabular}{|c|c|c|c|c|c|c|}
\hline Entry & Porphyrin & Heterocycle & Catalytic system & Solvent, temp., ${ }^{\circ} \mathrm{C}$ & Product & Yield, $\%^{a}$ \\
\hline 1 & 1 & $\begin{array}{l}\text { benzothiazole } \\
\text { (1 equiv) }\end{array}$ & $\begin{array}{c}\mathrm{Pd}(\mathrm{OAc})_{2} / \text { DavePhos } \\
(20: 20 \mathrm{~mol} \%)\end{array}$ & DMF, 150 & 3 & 8 \\
\hline 2 & 1 & $\begin{array}{l}\text { benzothiazole } \\
\text { ( } 2 \text { equiv) }\end{array}$ & $\begin{array}{c}\mathrm{Pd}(\mathrm{dba})_{2} / \text { DavePhos } \\
(20: 22 \mathrm{~mol} \%)\end{array}$ & DMF, 150 & 3 & 32 \\
\hline 3 & 1 & $\begin{array}{l}\text { benzothiazole } \\
\text { ( } 2 \text { equiv) }\end{array}$ & $\begin{array}{c}\mathrm{Pd}(\mathrm{dba})_{2} / \text { DavePhos } \\
(20: 22 \mathrm{~mol} \%)\end{array}$ & dioxane, 100 & 3 & 34 \\
\hline 4 & 1 & $\begin{array}{c}\text { benzothiazole } \\
\text { ( } 0.5 \text { equiv })\end{array}$ & $\begin{array}{c}\mathrm{Pd}(\mathrm{dba})_{2} / \text { DavePhos } \\
(20: 22 \mathrm{~mol} \%)\end{array}$ & DMF, 150 & 3 & 19 \\
\hline 5 & 1 & $\begin{array}{l}\text { benzoxazole } \\
\text { (1 equiv) }\end{array}$ & $\begin{array}{c}\mathrm{Pd}(\mathrm{dba})_{2} / \text { DavePhos } \\
(20: 22 \mathrm{~mol} \%)\end{array}$ & dioxane, 100 & 4 & 83 \\
\hline 6 & 2 & $\begin{array}{l}\text { benzoxazole } \\
\text { ( } 2 \text { equiv) }\end{array}$ & $\begin{array}{c}\mathrm{Pd}(\mathrm{dba})_{2} / \text { DavePhos } \\
(20: 22 \mathrm{~mol} \%)\end{array}$ & dioxane, 100 & 5 & 45 \\
\hline
\end{tabular}

aYields of isolated products after column chromatography.

proceeds in accordance with the concerted metalation-deprotonation mechanism $[33,34]$. We also investigated the reaction of zinc meso-(3-bromophenyl)porphyrinate (2) with a less active bromine atom in the reaction with benzoxazole (Table 1 , entry 6$)$. In this case the yield of the coupling product 5 was moderate (45\%) though we employed 2 equiv of the heteroarene. The analogous reaction with benzothiazole was unsuccessful.

Further we decided to test the catalytic conditions proposed by Osuka for the $\beta$-arylation of porphyrins with bromoarenes [28] and investigated the reactions of the zinc porphyrinates $\mathbf{1}$ and $\mathbf{2}$ with benzoxazole ( 2 equiv) or benzothiazole ( 2 equiv) in the presence of $\mathrm{Pd}(\mathrm{OAc})_{2}(20 \mathrm{~mol} \%)$ without phosphine ligand with pivalic acid as an additive ( 2.5 equiv). The reactions of $\mathbf{1}$ with benzoxazole and of $\mathbf{2}$ with benzothiazole were run in dimethylacetamide (DMA) at $100{ }^{\circ} \mathrm{C}$ and produced only $14 \%$ yield of the coupling product 6 with benzothiazole while with benzoxazole no reaction was observed (Scheme 2). The change of $\mathrm{Pd}(\mathrm{OAc})_{2}$ for $\mathrm{Pd}(\mathrm{dba})_{2}$ fully hindered the reaction in both cases, while the application of $\mathrm{Pd}\left(\mathrm{PPh}_{3}\right)_{4}$ allowed to obtain product 3 in 18\% yield and slightly increased the yield of compound 6 to $20 \%$. The accurate investigation of the mechanism of the process was not described in literature, only in the work by Hartwig [35] $\mathrm{Pd}(\mathrm{OAc})_{2}$ without any additional ligand was shown to be advantageous over catalytic systems with phosphine ligands. Osuka also used this approach for $\beta$-arylation of porphyrins. In this ligandless reaction the $\operatorname{Pd}(0)$ species from palladium acetate could be provided by the traces of amine present in DMA, and the catalytic cycle proceeds via $\mathrm{Pd}(\mathrm{II})$ after oxidative addition. However, $\operatorname{Pd}(\mathrm{dba})_{2}$ as a source of $\operatorname{Pd}(0)$ may be unfavorable in the absence of the phosphine ligand and in situ reduced palladium is sometimes more preferable. A better result obtained with $\mathrm{Pd}\left(\mathrm{PPh}_{3}\right)_{4}$ supports this consideration.

In our further investigations we abandoned this catalytic protocol which was shown to be improper for our reagents and tried another one, proposed by Z.-Z. Huang [36] which employs both $\mathrm{Pd}(\mathrm{II})$ and $\mathrm{Cu}(\mathrm{II})$ catalyst precursors. The reactions of zinc porphyrinates $\mathbf{1}$ and $\mathbf{2}$ with heteroarenes were catalyzed with $\mathrm{Pd}(\mathrm{OAc})_{2} / \mathrm{Cu}(\mathrm{OAc})_{2}(20: 20 \mathrm{~mol} \%)$ catalytic system in the

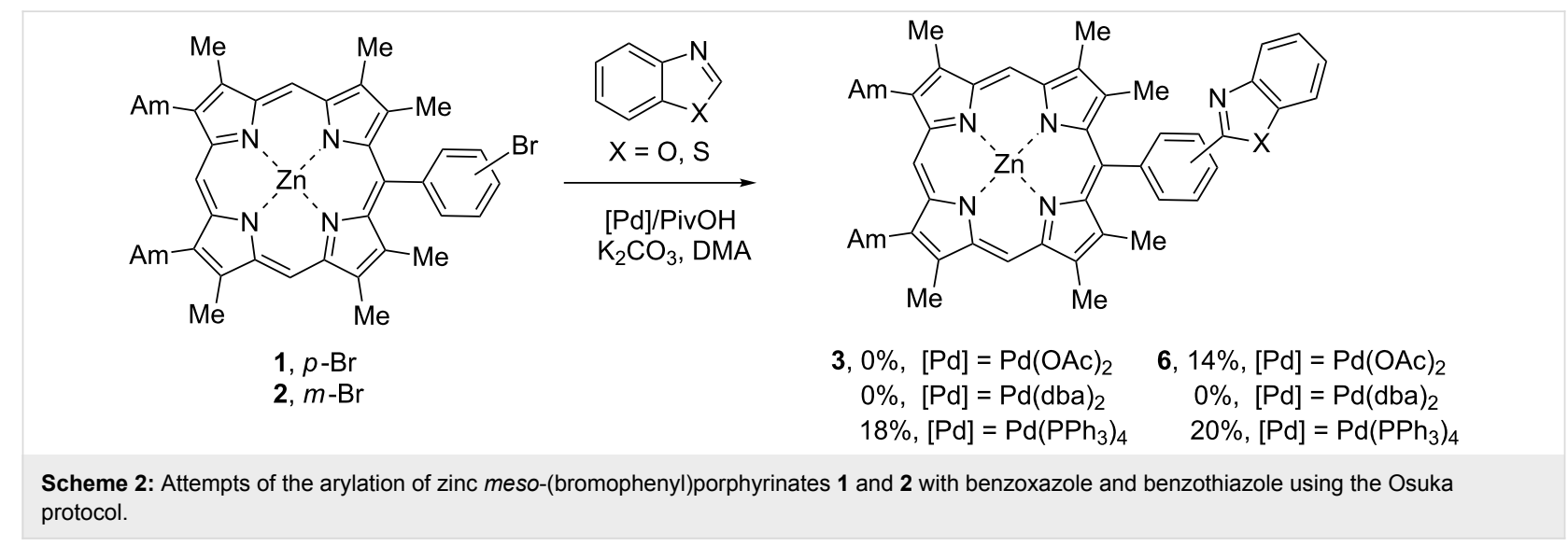


presence of 1 equiv $\mathrm{PPh}_{3}$ ligand and $\mathrm{K}_{2} \mathrm{CO}_{3}$ as a base (Scheme 3). All reactions were run in boiling toluene for $24 \mathrm{~h}$. At first the ratio of porphyrin $\mathbf{1}$ to heteroarene was taken as 1:0.9 (Table 2, entries 1, 3, and 6) and with benzothiazole and benzoxazole it provided moderate yields of the target compounds 3 and 4 (35 and 47\%, respectively). In the reaction with $\mathrm{N}$-methylbenzimidazole no coupling product could be isolated in a pure state due to the formation of the complex reaction mixture and insufficient conversion of the starting compounds.
The application of 2 equiv of heteroarenes like in protocols described above led to a notable improvement of the yields which attained $60 \%$ for the compounds 3 and 4 (Table 2, entries 2 and 4), and we also managed to isolate an individual coupling product with $N$-methylbenzimidazole (Table 2, entry 7). The increase in the reaction time ( $40 \mathrm{~h}$ instead of $24 \mathrm{~h}$ ) was not significant for the arylation with benzoxazole (Table 2, entry 5) but it helped to obtain compound 7 in a high yield (Table 2, entry 8). With benzothiazole the increase in the reaction time

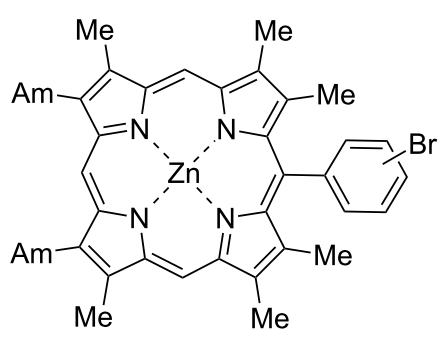

1, $p-\mathrm{Br}$

2, $m-\mathrm{Br}$

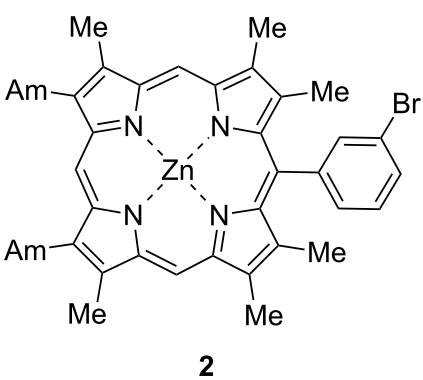

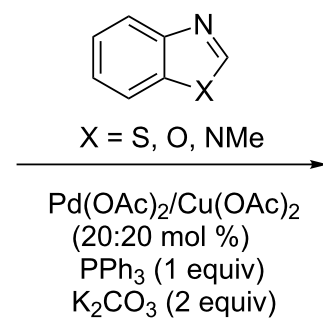

$\mathrm{K}_{2} \mathrm{CO}_{3}$ (2 equiv)

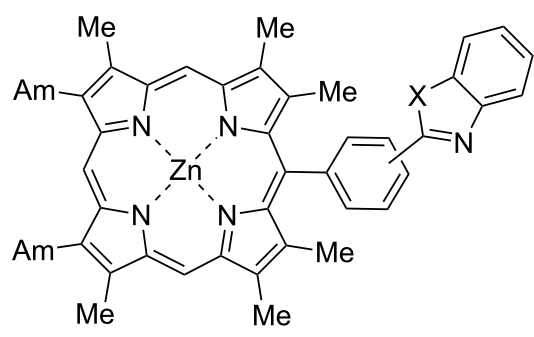

$3, \mathrm{X}=\mathrm{S}, p-$

4, $\mathrm{X}=\mathrm{O}, p$ -

$5, X=O, m$ -

6, $\mathrm{X}=\mathrm{S}, \mathrm{m}$ -

7, X $=$ NMe, $p-$

8, $X=$ NMe, $m$ -

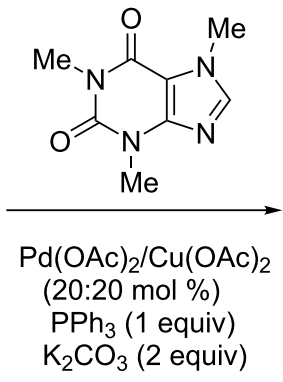

$\mathrm{PPh}_{3}$ (1 equiv)

$\mathrm{K}_{2} \mathrm{CO}_{3}$ (2 equiv)<smiles>Cn1c(=O)c2c(nc(-c3ccccc3)n2C)n(C)c1=O</smiles>

9, $95 \%$

Scheme 3: Arylation of zinc meso-(bromophenyl)porphyrinates 1, 2 with benzothiazole, benzoxazole, $N$-methylbenzimidazole and caffeine.

Table 2: Arylation of zinc meso-(bromophenyl)porphyrinates 1, 2 with benzothiazole, benzoxazole, $\mathrm{N}$-methylbenzimidazole and caffeine (conditions: $\mathrm{Pd}(\mathrm{OAc})_{2} / \mathrm{Cu}(\mathrm{OAc})_{2}(20: 20 \mathrm{~mol} \%), \mathrm{PPh}_{3}, 1$ equiv, $\mathrm{K}_{2} \mathrm{CO}_{3}$, toluene, $\left.110^{\circ} \mathrm{C}\right)$.

\begin{tabular}{|c|c|c|c|c|c|c|}
\hline Entry & Porphyrin & Heterocycle & Porphyrin to heterocycle ratio & Time, $\mathrm{h}$ & Product & Yield, \% \\
\hline 1 & 1 & benzothiazole & $1: 0.9$ & 24 & 3 & 35 \\
\hline 2 & 1 & benzothiazole & $1: 2$ & 24 & 3 & 60 \\
\hline 3 & 1 & benzoxazole & $1: 0.9$ & 24 & 4 & 47 \\
\hline 4 & 1 & benzoxazole & $1: 2$ & 24 & 4 & 60 \\
\hline 5 & 1 & benzoxazole & $1: 2$ & 40 & 4 & 67 \\
\hline 6 & 1 & $N$-methylbenzimidazole & $1: 0.9$ & 24 & 7 & 0 \\
\hline 7 & 1 & $N$-methylbenzimidazole & $1: 2$ & 24 & 7 & 29 \\
\hline 8 & 1 & $N$-methylbenzimidazole & $1: 2$ & 40 & 7 & 79 \\
\hline 9 & 2 & benzothiazole & $1: 2$ & 40 & 6 & 55 \\
\hline 10 & 2 & benzoxazole & $1: 2$ & 40 & 5 & 50 \\
\hline 11 & 2 & $N$-methylbenzimidazole & $1: 2$ & 40 & 8 & 90 \\
\hline 12 & 2 & caffeine & $1: 2$ & 40 & 9 & 95 \\
\hline
\end{tabular}


led not only to a higher conversion of the starting compounds but also to a substantial destruction of the reaction product. This effect explains inefficiency of the longer reaction time for the synthesis of product $\mathbf{3}$.

The reactions with a less reactive meso-(3-bromophenyl)porphyrin 2 were run for $40 \mathrm{~h}$ using 2 equiv of heteroarenes and provided 50-55\% yields of the corresponding coupling products with benzoxazole and benzothiazole (Table 2, entries 9 and 10 ), and with $N$-methylbenzimidazole the yield of 8 reached $90 \%$ (Table 2, entry 11). However, the best result was obtained with caffeine ( $95 \%$, Table 2 , entry 12$)$ which turned to be the most active reagent in the series.

The mechanism of this catalytic process is still not clear. Indeed, $\mathrm{Cu}(\mathrm{II})$ which is present in an equimolar amount compared to Pd(II) should oxidize zero valent palladium emerging in the course of the reduction with excess $\mathrm{PPh}_{3}$ (like in the Wacker process). A plausible explanation is that $\mathrm{Cu}(\mathrm{II})$ metalates heteroarene in the presence of $\mathrm{K}_{2} \mathrm{CO}_{3}$ forming $\mathrm{Het}-\mathrm{Cu}$ $\mathrm{OAc}$ species and this process proceeds faster than the oxidation of $\operatorname{Pd}(0)$. Then one may suppose the transmetalation reaction at heteroarene according to Scheme 4 which provides the formation of Ar-Pd-Het intermediate giving the target coupling product. Probably this path is better than direct palladation of heteroarenes. As a result, the needed excess of heteroarene is dramatically decreased (from 10-20 equiv used by Osuka to 2 equiv in the present protocol).

At the next step of our investigation we employed zinc di-meso(bromophenyl)porphyrinates 10-12 in the reactions with the same heteroarenes to compare two catalytic systems (Scheme 5, Table 3). The reaction were run under optimized conditions for $24 \mathrm{~h}$ in the case of benzothiazole and $40 \mathrm{~h}$ in the case of benzoxazole and $N$-methylbenzimidazole using 4 equiv of heteroarenes, the amounts of the catalysts were taken as described above. The reactions with these porphyrins turned to be more capricious and the results depended seriously on the nature of both reagents. The arylation of porphyrin $\mathbf{1 0}$ with benzoxazole in the presence of $\mathrm{Pd}(\mathrm{II}) / \mathrm{Cu}$ (II) catalytic system in toluene provided a diarylated product 13 in a good yield $(65 \%$, Table 3, entry 1). However, a less reactive benzothiazole gave only monoarylated product 14 in $64 \%$ yield (Table 3 , entry 2 ). Surprisingly, in the case of $N$-methylbenzimidazole we achieved $83 \%$ yield of the monoarylated product 15 , but no target diarylated product was obtained (Table 3, entry 3). Alternative catalytic system $\mathrm{Pd}(\mathrm{dba})_{2} /$ DavePhos proved to be efficient for the synthesis of the diarylated product $\mathbf{1 6}$ in the reaction of benzoxazole with porphyrin 11 (Table 3, entry 4) which is quite similar to porphyrin $\mathbf{1 0}$ (it contains $n$-amyl substitutents instead of $n$-propyl groups), however, this catalytic system was unable to provide the arylation with benzothiazole or $N$-benzimidazole under the same conditions.

Isomeric zinc di-meso-(3-bromophenyl)porphyrinate $\mathbf{1 2}$ was able to form only monoarylated derivative $\mathbf{1 7}$ from benzothiazole in a low yield (Table 3 , entry 5 ) in the presence of the catalytic system $\mathrm{Pd}(\mathrm{OAc})_{2} / \mathrm{Cu}(\mathrm{OAc})_{2} / \mathrm{PPh}_{3}$ but could not provide the arylation products with either benzoxazole or $N$-methylbenzimidazole. These facts imply that one cannot judge the reactivity of any hetoeroarene itself but need to refer to a pair of reagents also indicating a certain catalytic system in each case.

In order to explore the scope and limitations of the studied approach we carried out the reaction with zinc tetrakis(4-bromophenyl)porphyrinate 18 using 8 equiv of the corresponding heteroarenes, $40 \mathrm{~mol} \%$ catalyst, 2.5 equiv $\mathrm{PPh}_{3}$ and 5 equiv $\mathrm{K}_{2} \mathrm{CO}_{3}$ (Scheme 6). It was found out that with benzoxazole the target tetraarylated derivative 19 was isolated in $14 \%$ yield, and triarylated compound $\mathbf{2 0}$ was the major product obtained in $80 \%$ yield. With benzothiazole and $N$-benzimidazole the same reactions provided only inseparable mixtures of corresponding tri- and tatraarylated derivatives.

The investigation of the UV-vis spectra of the arylated monophenylporphyrins 3-9 disclosed that they possess almost

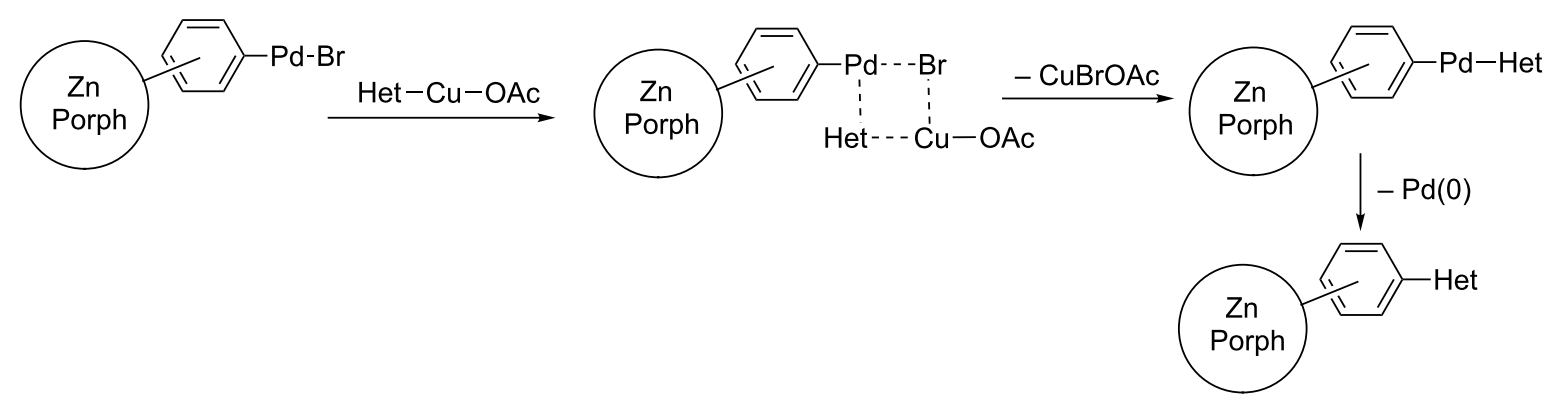




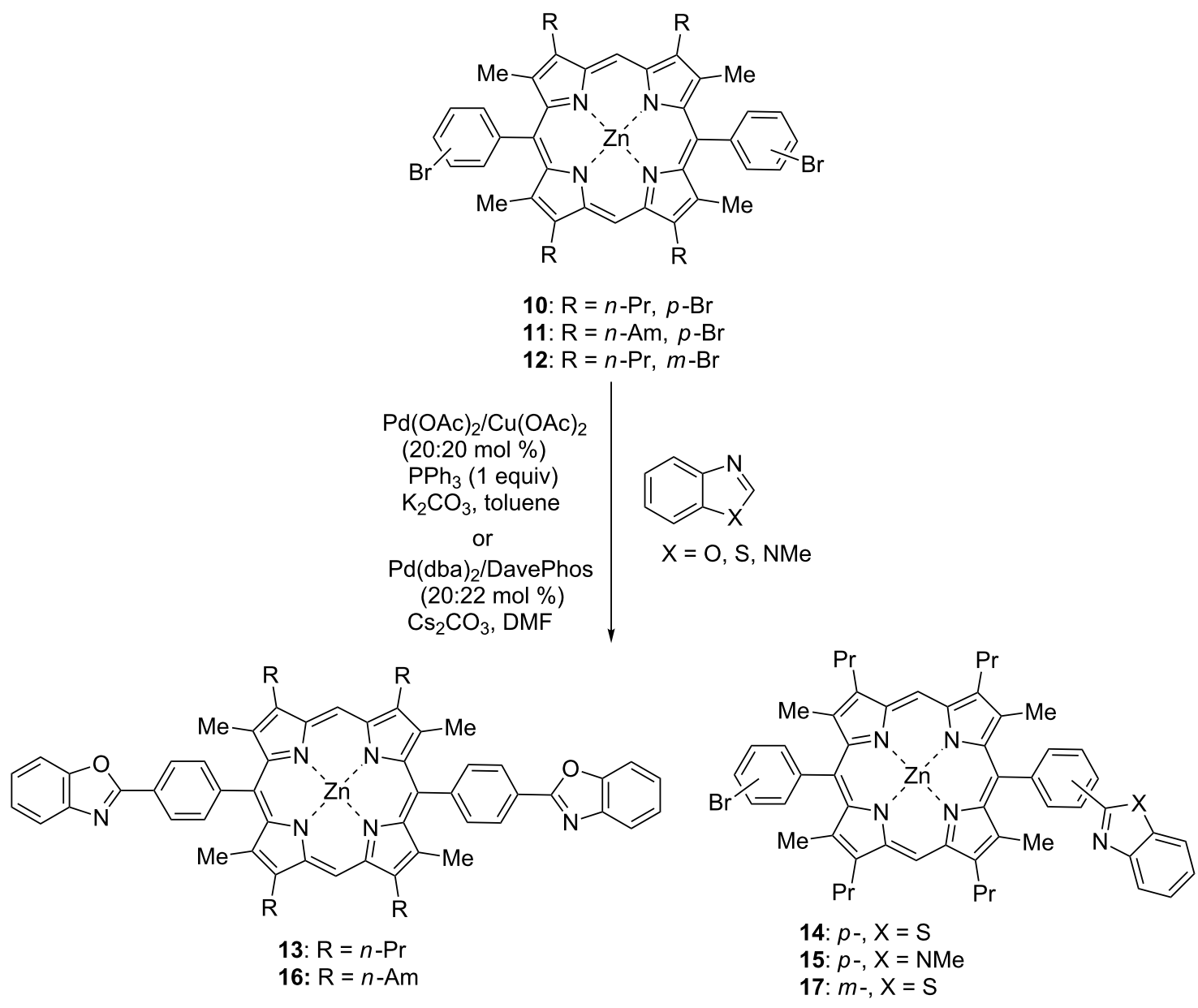

Scheme 5: Dirylation of zinc di-meso-(bromophenyl)porphyrinates 10-12 with benzothiazole, benzoxazole and $\mathrm{N}$-methyl benzimidazole.

Table 3: Diarylation of zinc di-meso-(bromophenyl)porphyrinates 10-12 with benzothiazole, benzoxazole and $N$-methylbenzimidazole.

\begin{tabular}{|c|c|c|c|c|c|c|}
\hline Entry & Porphyrin & Heterocycle & Catalytic system & Type of substitution & Product & Yield, \% \\
\hline 1 & 10 & benzoxazole & $\mathrm{Pd}(\mathrm{OAc})_{2} / \mathrm{Cu}(\mathrm{OAc})_{2} / \mathrm{PPh}_{3}$ & disubstitution & 13 & 65 \\
\hline 2 & 10 & benzothiazole & $\mathrm{Pd}(\mathrm{OAc})_{2} / \mathrm{Cu}(\mathrm{OAc})_{2} / \mathrm{PPh}_{3}$ & monosubstitution & 14 & 64 \\
\hline 3 & 10 & $N$-methylbenzimidazole & $\mathrm{Pd}(\mathrm{OAc})_{2} / \mathrm{Cu}(\mathrm{OAc})_{2} / \mathrm{PPh}_{3}$ & monosubstitution & 15 & 83 \\
\hline 4 & 11 & benzoxazole & $\mathrm{Pd}(\mathrm{dba})_{2} /$ DavePhos & disubstitution & 16 & 52 \\
\hline 5 & 12 & benzothiazole & $\mathrm{Pd}(\mathrm{OAc})_{2} / \mathrm{Cu}(\mathrm{OAc})_{2} / \mathrm{PPh}_{3}$ & monosubstitution & 17 & 19 \\
\hline
\end{tabular}

identical absorption maxima but somewhat differ in extinction values primarily due to the different sharpness of the bands (Table 4). The Soret band at $406 \mathrm{~nm}$ is naturally the most intensive while $Q$ bands at 535 and $570 \mathrm{~nm}$ are almost of the same intensities. Thus the maxima of the absorption bands in the products 3-9 are essentially the same as in the starting $\mathrm{Zn}$ porphyrinates 1 ( $\lambda_{\max } 572 \mathrm{~nm}(\lg \varepsilon 3.95), 536 \mathrm{~nm}(\lg \varepsilon 3.98)$, $406 \mathrm{~nm}(\lg \varepsilon 5.56))$ [31] and 2 (571 nm (lg 84.42$), 534 \mathrm{~nm}(\lg \varepsilon$ $4.43), 405 \mathrm{~nm}(\lg \varepsilon 5.64))$, but extinction values are regularly smaller. The spectra of fluorescence (with extinction at Soret band) in all cases display two emission maxima at 586 and 636-638 nm, the first one being more intensive. It corresponds with the fluorescence spectra of zinc bromophenylporphyrinate.

The UV-vis spectra of diphenylporphyrins 13-15 (Table 4) possess absorption bands in the same region as their monophenyl analogues 3-9, but all maxima are slightly red-shifted. It fully corresponds with the absorption bands of the bis(4-bromo- 

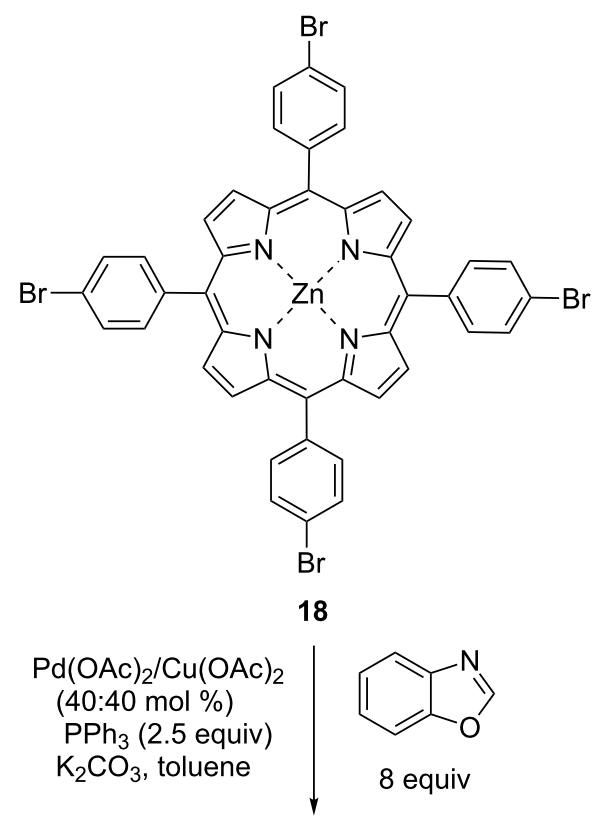

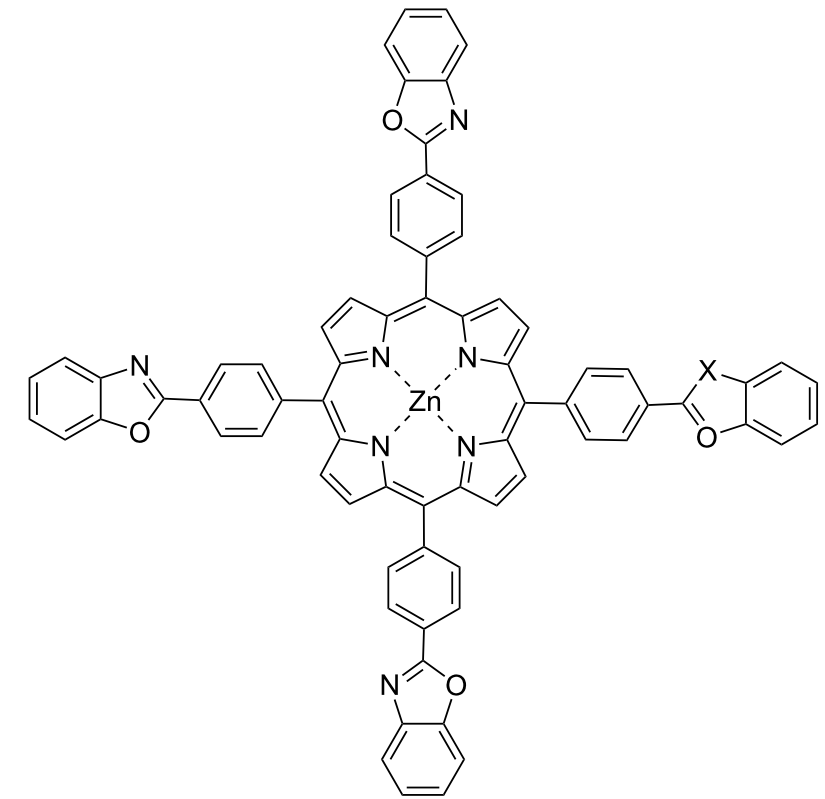

$19,14 \%$

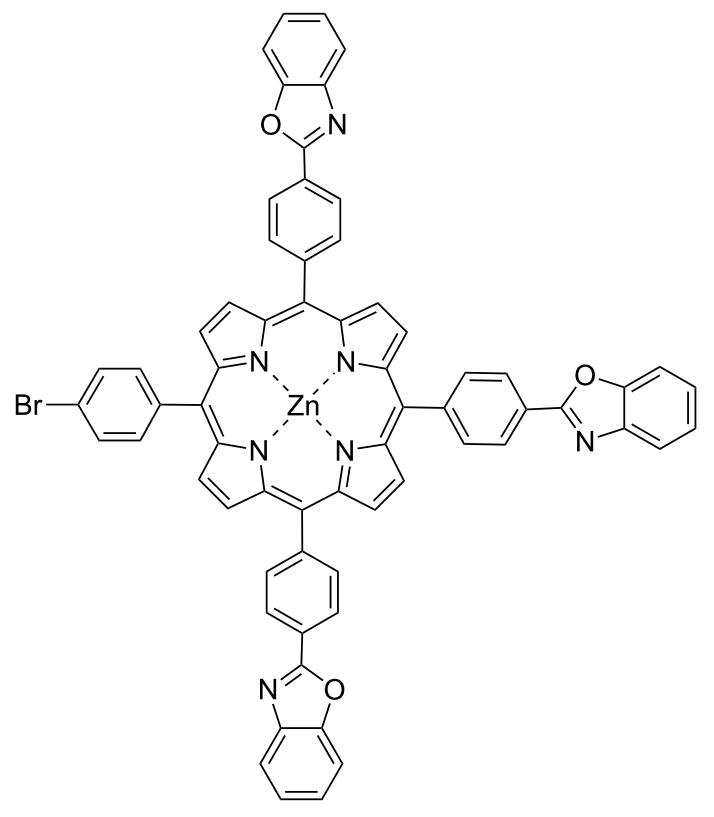

$20,80 \%$

Scheme 6: Polyarylation of zinc tetrakis-meso-(bromophenyl)porphyrinate 18 with benzoxazole.

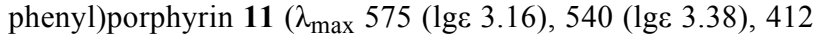
(lge 4.68)). There is no significant difference in the spectra of diarylated derivative 13 and monoarylated derivatives 14 and 15, one may note a slight bathochromic shift of the Soret band and higher extinction values for compound 13. The spectra of fluorescence are quite identical and are characterized by two emission bands at 592 and 640-642 nm. All these spectroscopic data demonstrate that the substitution of the bromine atom for heterocyclic moieties does not notably change absorption and emission spectra due to insignificant influence of the electronic properties of the substituents at the meso-phenyl rings on the electronic structure of the porphyrin core.

\section{Conclusion}

To sum up, the investigation of the arylation of zinc meso(bromophenyl)porphyrinates under different catalytic conditions revealed that the catalytic system $\mathrm{Pd}(\mathrm{OAc})_{2} / \mathrm{Cu}(\mathrm{OAc})_{2} /$ $\mathrm{PPh}_{3}$ was the most efficient and applicable to various pairs of the reagents. More successful arylation of 4-bromophenyl derivatives compared to 3-bromophenyl-substituted porphyrinates is 
Table 4: UV-vis and fluorescence spectra of the arylated porphyrins 3-9, 13-15 (in $\mathrm{CH}_{2} \mathrm{Cl}_{2}$ ).

\begin{tabular}{|c|c|c|c|}
\hline Compound & $\lambda_{\max }, \mathrm{nm}$ & $\lg \varepsilon$ & $\lambda_{\mathrm{em}}, \mathrm{nm}$ \\
\hline 3 & $\begin{array}{l}406 \\
535 \\
570\end{array}$ & $\begin{array}{l}4.59 \\
2.94 \\
2.80\end{array}$ & $\begin{array}{l}586 \\
636\end{array}$ \\
\hline 4 & $\begin{array}{l}406 \\
535 \\
571\end{array}$ & $\begin{array}{l}4.89 \\
3.49 \\
3.47\end{array}$ & $\begin{array}{l}586 \\
636\end{array}$ \\
\hline 5 & $\begin{array}{l}406 \\
535 \\
571\end{array}$ & $\begin{array}{l}4.58 \\
3.38 \\
3.40\end{array}$ & $\begin{array}{l}586 \\
636\end{array}$ \\
\hline 6 & $\begin{array}{l}406 \\
535 \\
571\end{array}$ & $\begin{array}{l}4.84 \\
3.47 \\
3.44\end{array}$ & $\begin{array}{l}586 \\
636\end{array}$ \\
\hline 7 & $\begin{array}{l}406 \\
535 \\
571\end{array}$ & $\begin{array}{l}4.84 \\
3.28 \\
3.23\end{array}$ & $\begin{array}{l}586 \\
638\end{array}$ \\
\hline 8 & $\begin{array}{l}406 \\
535 \\
571\end{array}$ & $\begin{array}{l}4.50 \\
3.30 \\
3.26\end{array}$ & $\begin{array}{l}586 \\
636\end{array}$ \\
\hline 9 & $\begin{array}{l}406 \\
533 \\
571\end{array}$ & $\begin{array}{l}4.42 \\
1.94 \\
2.08\end{array}$ & $\begin{array}{l}586 \\
636\end{array}$ \\
\hline 13 & $\begin{array}{l}413 \\
539 \\
574\end{array}$ & $\begin{array}{l}4.93 \\
3.52 \\
3.10\end{array}$ & $\begin{array}{l}592 \\
642\end{array}$ \\
\hline 14 & $\begin{array}{l}410 \\
538 \\
573\end{array}$ & $\begin{array}{l}4.50 \\
2.91 \\
2.21\end{array}$ & $\begin{array}{l}592 \\
640\end{array}$ \\
\hline 15 & $\begin{array}{l}410 \\
536 \\
572\end{array}$ & $\begin{array}{l}4.70 \\
2.93 \\
2.13\end{array}$ & $\begin{array}{l}592 \\
642\end{array}$ \\
\hline
\end{tabular}

due to a more reactive halogen in these compounds. Generally, benzoxazole and in some cases $N$-methylbenzimidazole demonstrated the advantage over benzothiazole in the catalytic coupling probably due to lower stability of the latter under the reaction conditions studied. As a result, the possibility of successful diarylation of zinc di-meso-(4-bromophenyl)porphyrinate and even tetraarylation of zinc tetrakis-meso-(bromophenyl)porphyrinate with benzoxazole was shown.

\section{Supporting Information}

\section{Supporting Information File 1}

Experimental procedures, characterization and spectral data for synthesized compounds 2-9, 11, 12, 13-17, 19, 20.

[http://www.beilstein-journals.org/bjoc/content/ supplementary/1860-5397-13-152-S1.pdf]

\section{Acknowledgements}

Authors thank RSF (grant N 14-23-00186) and RFBR (grant N 16-29-10685) for financial support, ANK thanks RFBR (grant N 16-33-00175mol).

\section{References}

1. Ethirajan, M.; Patel, N. K.; Pandey, J. R. Porphyrin-Based Multifunctional Agents for Tumor-Imaging and Photodynamic Therapy (PDT). In Handbook of Porphyrin Science: With Applications to Chemistry, Physics, Materials Science, Engineering, Biology and Medicine. V. 4: Phototherapy,. Radioimmunotherapy and Imaging; Kadish, K. M.; Smith, K. M.; Guilard, R., Eds.; World Scientific Publishing, 2010.

2. Pereira, P. M. R.; Tomé, J. P. C.; Fernandes, R. Molecular Targeted Photodynamic Therapy for Cancer. In Handbook of Porphyrin Science: With Applications to Chemistry, Physics, Materials Science, Engineering, Biology and Medicine. V. 39: Towards Diagnostics and Treatment of Cancer; Kadish, K. M.; Smith, K. M.; Guilard, R., Eds.; World Scientific Publishing, 2016.

3. Liang, X.; Li, X.; Jing, L.; Yue, X.; Dai, Z. Biomaterials 2014, 35, 6379-6388. doi:10.1016/j.biomaterials.2014.04.094

4. Huang, S.-T.; Hsei, I.-J.; Chen, C. Bioorg. Med. Chem. 2006, 14, 6106-6119. doi:10.1016/j.bmc.2006.05.007

5. Weekes, A. A.; Westwell, A. D. Curr. Med. Chem. 2009, 16, 2430-2440. doi:10.2174/092986709788682137

6. Milgrom, L. R.; Dempsey, P. J. F.; Yahioglu, G. Tetrahedron 1996, 52, 9877-9890. doi:10.1016/0040-4020(96)00520-0

7. Ozeki, H.; Nomoto, A.; Ogawa, K.; Kobuke, Y.; Murakami, M.; Hosoda, K.; Ohtani, M.; Nakashima, S.; Miyasaka, H.; Okada, T. Chem. - Eur. J. 2004, 10, 6393-6401. doi:10.1002/chem.200400624

8. Gryko, D.; Lindsey, J. S. J. Org. Chem. 2000, 65, 2249-2252. doi:10.1021/jo9918100

9. Rauch, V.; Wytko, J. A.; Takahashi, M.; Kikkawa, Y.; Kanesato, M.; Weiss, J. Org. Lett. 2012, 14, 1998-2001. doi:10.1021/ol300488y

10. Kamal, A.; Ahmed, S. K.; Reddy, K. S.; Khan, M. N. A.; Shetty, R. V. C. R. N. C.; Siddhardha, B.; Murty, U. S. N.; China, A.; Nagaraja, V. Lett. Drug Des. Discovery 2007, 4, 550-556. doi:10.2174/157018007782794563

11. Shao, P.; Huang, B.; Chen, L.; Liu, Z.; Qin, J.; Gong, H.; Ding, S.; Wang, Q. J. Mater. Chem. 2005, 15, 4502-4506. doi:10.1039/B507958F

12. Karlsson, H. J.; Bergqvist, M. H.; Lincoln, P.; Westman, G. Bioorg. Med. Chem. 2004, 12, 2369-2384. doi:10.1016/j.bmc.2004.02.006

13. Laskar, I. R.; Chen, T.-M. Chem. Mater. 2004, 16, 111-117. doi:10.1021/cm030410x

14. Wang, Y.; Mathis, C. A.; Huang, G.-F.; Debnath, M. L.; Holt, D. P.; Shao, L.; Klunk, W. E. J. Mol. Neurosci. 2003, 20, 255-260. doi:10.1385/JMN:20:3:255

15. Harrop, T. C.; Rodriguez, K.; Mascharak, P. K. Synth. Commun. 2003, 33, 1943-1949. doi:10.1081/SCC-120020209

16. Chakraborti, A. K.; Rudrawar, S.; Kaur, G.; Sharma, L. Synlett 2004, 1533-1536. doi:10.1055/s-2004-829089

17. Wu, C.; Wei, J.; Gao, K.; Wang, Y. Bioorg. Med. Chem. 2007, 15, 2789-2796. doi:10.1016/j.bmc.2006.11.022

18. Wu, C.; Cai, L.; Wei, J.; Pike, V. W.; Wang, Y. Curr. Alzheimer Res. 2006, 3, 259-266. doi:10.2174/156720506777632862

19. Racane, L.; Tralic-Kulenovic, V.; Fiser-Jakic, L.; Boykin, D. W.; Karminski-Zamola, G. Heterocycles 2001, 55, 2085-2098. doi:10.3987/COM-01-9305

20. Choi, S.-J.; Park, H. J.; Lee, S. K.; Kim, S. W.; Han, G.; Choo, H.-Y. P. Bioorg. Med. Chem. 2006, 14, 1229-1235. doi:10.1016/j.bmc.2005.09.051

21. Mourtas, S.; Gatos, D.; Barlos, K. Tetrahedron Lett. 2001, 42 , 2201-2204. doi:10.1016/S0040-4039(01)00109-5 
22. Gupta, S. D.; Singh, H. P.; Moorthy, N. S. H. N. Synth. Commun. 2007, 37, 4327-4329. doi:10.1080/00397910701575657

23. Hata, H.; Shinokubo, H.; Osuka, A. J. Am. Chem. Soc. 2005, 127, 8264-8265. doi:10.1021/ja051073r

24. Hata, H.; Yamaguchi, S.; Mori, G.; Nakazono, S.; Katoh, T.; Takatsu, K.; Hiroto, S.; Shinokubo, H.; Osuka, A. Chem. - Asian J. 2007, 2, 849-859. doi:10.1002/asia.200700086

25. Chen, J.; Aratani,, N.; Shinokubo, H.; Osuka, A. Chem. - Asian J. 2009, 4, 1126-1133. doi:10.1002/asia.200900053

26. Kawamata, Y.; Tokuji, S.; Yorimitsu, H.; Osuka, A Angew. Chem., Int. Ed. 2011, 50, 8867-8870. doi:10.1002/anie.201102318

27. Tokuji, S.; Awane, H.; Yorimitsu, H.; Osuka, A. Chem. - Eur. J. 2013, 19, 64-68. doi:10.1002/chem.201203742

28. Yamamoto, Y.; Tokuji, S.; Tanaka, T.; Yorimitsu, H.; Osuka, A. Asian J. Org. Chem. 2013, 2, 320-324. doi:10.1002/ajoc.201200198

29. Yorimitsu, H.; Osuka, A. Asian J. Org. Chem. 2013, 2, 356-373. doi:10.1002/ajoc.201200183

30. Shen, K.; Fu, Y.; Li, J.-N.; Liu, L.; Guo, Q.-X. Tetrahedron 2007, 63, 1568-1576. doi:10.1016/j.tet.2006.12.032

31. Mikhalitsyna, E. A.; Tyurin, V. S.; Nefedov, S. E.; Syrbu, S. A.; Semeikin, A. S.; Koifman, O. I.; Beletskaya, I. P. Eur. J. Inorg. Chem. 2012, 5979-5990. doi:10.1002/ejic.201200868

32. Sánchez, R. S.; Zhuravlev, F. A. J. Am. Chem. Soc. 2007, 129, 5824-5825. doi:10.1021/ja0679580

33. Gorelsky, S. I.; Lapointe, D.; Fagnou, K. J. Am. Chem. Soc. 2008, 130 10848-10849. doi:10.1021/ja802533u

34. Lapointe, D.; Fagnou, K. Chem. Lett. 2010, 39, 1118-1126. doi:10.1246/cl.2010.1118

35. Tan, Y.; Hartwig, J. F. J. Am. Chem. Soc. 2011, 133, 3308-3311. doi:10.1021/ja1113936

36. Yan, X.-M.; Mao, X.-R.; Huang, Z.-Z. Heterocycles 2011, 83, 1371-1376. doi:10.3987/COM-11-12176

\section{License and Terms}

This is an Open Access article under the terms of the Creative Commons Attribution License (http://creativecommons.org/licenses/by/4.0), which permits unrestricted use, distribution, and reproduction in any medium, provided the original work is properly cited.

The license is subject to the Beilstein Journal of Organic Chemistry terms and conditions:

(http://www.beilstein-journals.org/bjoc)

The definitive version of this article is the electronic one which can be found at: $\underline{\text { doi:10.3762/bjoc. } 13.152}$ 